\title{
FATIGUE DAMAGE OF V-LOCK CHAIN RING UNDER RANDOM LOAD
}

\author{
Qiang Zhang a,b, \\ Haijian Wang ${ }^{\mathrm{b}}$, \\ Tong Guo ${ }^{\text {, }}$ \\ a) The State Key Laboratory of Mechanical Transmissions, Chongqing University,China \\ ${ }^{b}$ College of Mechanical Engineering, Liaoning Technical University, Postal 123000,China
}

\begin{abstract}
To study the influence of the random load on the V-lock chain ring for mining, the numerical simula-tion technology is used. The dynamic tension is obtained by using the dynamic model of the plough. The life and damage nephograms are obtained by using ANSYS Workbench. The analysis results show that the short fatigue life region of the V-lock chain ring for mining is mainly concentrated on the transition region between the medial straight edge and arc, and the fatigue damage of the link chain on the side of the motion direction of the plow head is larger than that on the other side. This link chain has strong anti-fatigue performance.
\end{abstract}

Keywords: V-lock chain ring for mining; dynamic model; fatigue damage; random load; finite element; sensitivi-ty analysis

\section{INTRODUCTION}

The link chain is the independent component which is used for connecting the chain. The link chain is very widely used in many special equipments of the coal mine and equipments with haulage chain, such as the scraper conveyor, transfer machine, plough, cast stone scraper conveyor and fishing mechanical. It is also widely used on port transport business. Due to the special working condition, the link chain often generates the fracture phenomenon. Once the link chain is ruptured, the whole equipment will be in paralysis conditions which will seriously affect the normal production. The chain rupture accident will cause not only the serious economic loss but also the fatal accident caused by finding the fractured chain at the side of the coal wall.
Therefore, the quality performance level of the link chain is one of the main indexes for evaluating the whole aircraft reliability and machine life. Although the reliability of the chain has attracted broad attention of domestic and foreign scholars, little study has been carried on for the V-lock chain ring for mining.

This paper wants to research the fatigue damage of the V-lock chain ring for mining used in plough. The dynamic model of the plough is established to ob-tain the dynamic tensile force which is used as the random load. Time of the crack initiation of the link chain is calculated by using the finite elemental meth-od. The sensitivity of the V-lock chain ring for min-ing is analyzed. The results of this research can pro-vide some theoretical basis for the further study of the V-lock chain ring for mining. 


\section{DYNAMIC MODELING OF PLOUGH}

\section{BASIC HYPOTHESIZES}

To establish the dynamic model of the plough, the following hypothesizes are made.1)The mass and friction resistance of the plow chain are ignored because the mass of the plow head is generally several tons. 2) the vertical one-dimension dynamic mode of the plough is established by neglecting the influence of the transverse vibration of the chain. 3) the polygon effect of the sprocket isn't considered.

\section{MATHEMATICAL MODELING OF PLOUGH}

The plow system is composed of the plow head, plow chain, transmission, electric control system, hydraulic system and so on. The plough usually adopts the two-terminal motor drive. The work principle of the plough is that the plow head with the plane iron moves along the guide of the middle trough on the scraper conveyor under the traction of the plow chain, and the coal is loaded into the conveyor under the action of the pyriform incline of the plow head when the plane iron cuts the coal wall. The plough does the reciprocating motion along the working face under the haulage of the plow chain. As the plow chain runs in the closed sliding framework, the opportunity of the transverse vibration of the plow chain is very little, while the longitudinal vibration is relatively obvious. The vibration has an unfavorable influence on the operation of the plough. The variation of the tensile force will affect the service life of the plow chain. The plow chain is considered as the viscoelastic body according to the structure and actual operation situation of the plough. To make things easy to study, the dynamic model of the plough is simplified. The dy-namic model of the plough is shown in Figure 1.

$$
m \ddot{x}=F_{2}-F_{1}-F_{u}-F_{b}(t)
$$

Where $\mathrm{m}$ is the mass of the plow head, $\ddot{\mathrm{x}}$ is the acceleration of the plow head, $F_{1}$ is the tensile force of the chain between the plow head and driving device II, $\mathrm{F}_{2}$ is the tensile force of the chain between the plow head and driving device I, $\mathrm{F}_{\mathrm{u}}$ is the friction resistance of the plow head and $\mathrm{F}_{\mathrm{b}}(\mathrm{t})$ is the planning resistance of the plow head.

Where $\mathrm{x}$ is the displacement of the plow head, $\mathrm{x}$ is the velocity of the plow head, $\omega$ is the angular velocity of the drive sprocket, $\mathrm{R}$ is the pitch radius of the sprocket, $\mathrm{t}$ is the time, $\mathrm{k}_{1}$ and $\mathrm{c}_{1}$ are respectively the stiffness and damping of the chain between the plow head and driving device II, $\mathrm{k}_{2}$ and $\mathrm{c}_{2}$ are respectively the stiffness and damping of the chain between the plow head and driving device $\mathrm{I}$ and $\mathrm{F}_{\mathrm{vr}}$ is the surplus preload.

$$
F_{u}=\mu m g
$$

Where $\mu$ is the friction coefficient between the plow head and sliding framework, is the acceleration of gravity.

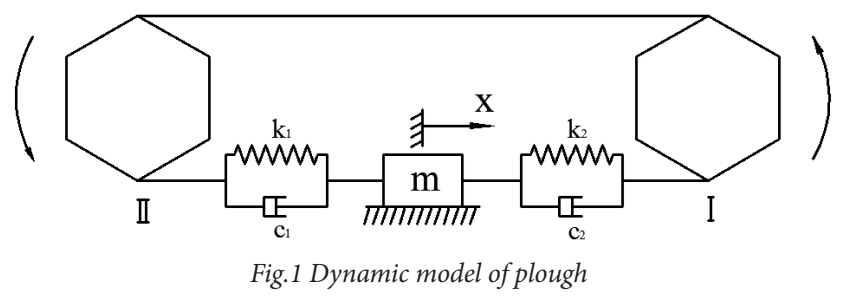

Due to the complex condition of the coal wall, the load of the plane iron caused by the coal wall is random. Many studies prove that the load of a single plane iron has the random nature. The study of the distribution functions of the cutting force and feeding distance force of the plane iron shows that the original $\Gamma$ distribution will change into the normal distribution when cutting the coal seam. The imbalance of the load distribution can be evaluated by the value of the var-iation coefficient. Therefore, the planning resistance of the plow head $\mathrm{F}_{\mathrm{b}}(\mathrm{t})$ is the normal distribution stationary random process.

The surplus preload of the plow chain is

$$
F_{v r}=F_{v}-\frac{3}{4}\left(F_{b}(t)+F_{u}\right)+\left(F_{b}(t)+F_{u}\right) \frac{x}{2 L}
$$

Where $\mathrm{L}$ is the face length (namely the distance between the centers of the two drive sprocket) and Fv is the pretightening force.

\section{SIMULATION MODELING AND ANALYSIS OF PLOUGH}

\section{SIMULATION MODELING OF PLOUGH}

The mathematical model of the plough established in above paragraphs is the nonlinear random kinetic equation which is timevarying, and the description of nonlinear factors is very complex. As it is difficult to obtain the accurate or approximate analytical solution by using the present solving methods, the numerical method is used to analyze the dynamic re-sponse of the plough further.

MATLAB/SIMULINK is used for establishing the simulation model. To get the time history of the tensile force of the plow chain, the kinetic equation of the single degree plough is solved under the random load caused by the coal wall. The simulation model of the plough is shown in Figure 2.

$$
\begin{gathered}
F_{1}=\left\{\begin{array}{cc}
k_{1}(x-\omega R t)+F_{v r}+c_{1}(\dot{x}-\omega R) & \left(k_{1}(x-\omega R t)+F_{v r}+c_{1}(\dot{x}-\omega R)\right)>0 \\
0 & \left(k_{1}(x-\omega R t)+F_{v r}+c_{1}(\dot{x}-\omega R)\right) \leq 0
\end{array}\right. \\
F_{2}=\left\{\begin{array}{cc}
k_{2}(\omega R t-x)+F_{v r}+c_{2}(\omega R-\dot{x}) & \left(k_{2}(\omega R t-x)+F_{v r}+c_{2}(\omega R-\dot{x})\right)>0 \\
0 & \left(k_{2}(\omega R t-x)+F_{v r}+c_{2}(\omega R-\dot{x})\right) \leq 0
\end{array}\right.
\end{gathered}
$$




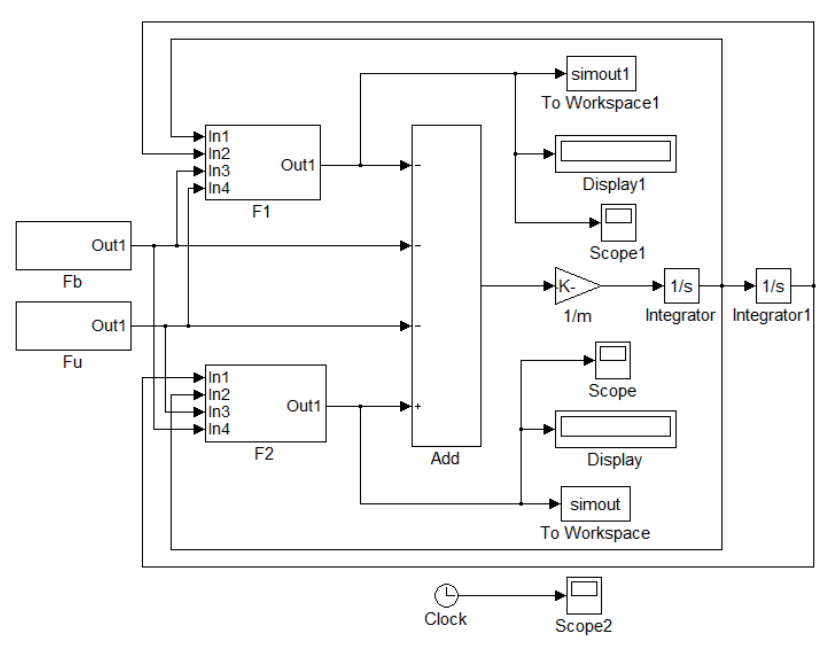

Fig.2 Simulation model of the plough

\section{DETERMINATION OF SIMULATION PARAMETERS}

The parameters of the plough of some coal mine are used as the basic simulation parameters, giving the example for calculating the fatigue life of the plow chain. The plow chain specification is $\varphi 30 \times 108 \mathrm{~mm}$; the mass of the plow head is $3.4 \times 103 \mathrm{~kg}$; the pitch radius $\mathrm{R}=0.243 \mathrm{~m}$; the angular velocity of the drive sprocket $\omega=6.17 \mathrm{rad} / \mathrm{s}$; the friction coefficient between the plow head and sliding framework $\mu=0.3$; the stiffness $\mathrm{cl}=\mathrm{c} 2=500 \mathrm{Ns} / \mathrm{m}$; the damping $\mathrm{k} 1=\mathrm{k} 2=6.95 \times 107$ $\mathrm{N} / \mathrm{m}$; the face length $\mathrm{L}=200 \mathrm{~m}$; the initial displacement $\mathrm{x} 0=0 \mathrm{~m}$, and the initial velocity $\dot{\mathrm{x}}=1.5 \mathrm{~m} / \mathrm{s}$. The planning resistance average is $50 \mathrm{KN}$, and the variation coefficient is 0.7 . The pretightening force is $50 \mathrm{KN}$. Let the simulation time be $120 \mathrm{~s}$.

\section{ANALYSIS OF TENSILE FORCE}

The time history of the plow chain tension obtained by numerical simulation is shown in Figure 3. Figure 3 shows that the tensile force of the chain is a dynamically changing process, and the tensile force at the initial time is the maximum which shows that the impact load will act on the chain when starting the chain. The waveform in Figure 3(a) is similar to the one in Figure 3(b), but their load amplitude level is different.

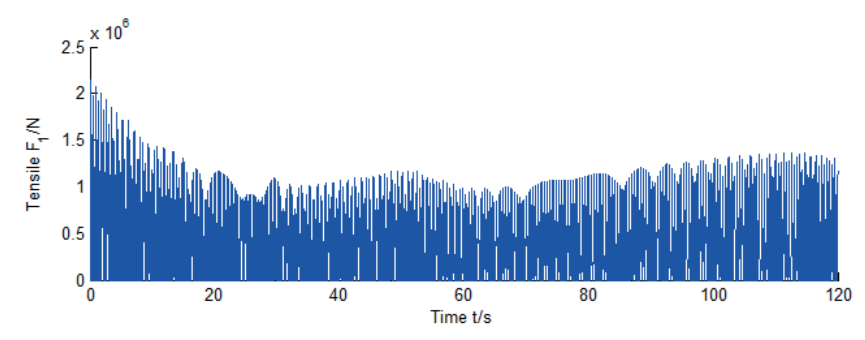

Fig.3(a) Tensile force $F_{1}$

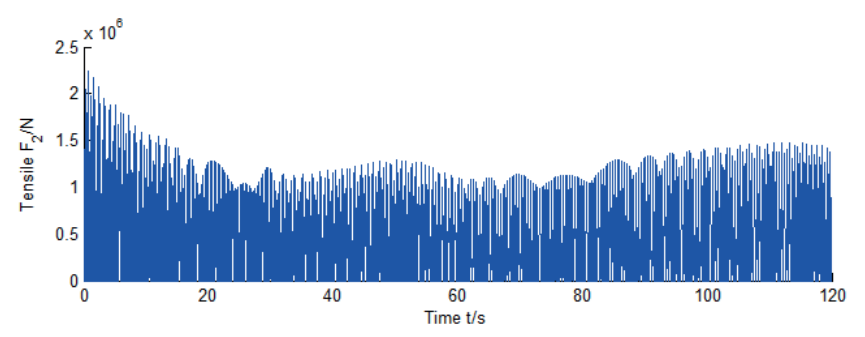

Fig.3(b) tensile force $\mathrm{F}_{2}$

\section{FATIGUE ANALYSIS OF V-LOCK CHAIN RING FOR MINING}

\section{ESTABLISHMENT OF FINITE ELEMENT MODEL}

The research object is the $\varphi 30 \times 108 \mathrm{~mm}$ V-lock chain ring for mining used in the plough. This link chain is composed of the semi ring and elastic pin. The transmission system of the link chain is a complicated structure, so it is very difficult to establish the complete dynamic model. The essence of the simula-tion modeling is to establish a similarity relation to the actual working condition. To establish the model conveniently, the link chain system is simplified on the basis of the actual working condition. The simplified model of the link chain system which is composed of two semi forging rings and a complete link chain is shown in Figure 4(a). Under the mesh order in ANSYS Workbench software, the automatic mesh genera-tion is performed in the simplified link chain system. The finite element model is shown in Figure 4(b). The element size is $4 \mathrm{~mm}$. The node number is 197924, and element number is 56840. The material of the link chain is $23 \mathrm{Mn}-\mathrm{Cr}-\mathrm{Ni}-\mathrm{Mo}$. The material parameters are as followings: Young's modulus is $210 \mathrm{GPa}$, and Poisson's ratio is 0.3 .
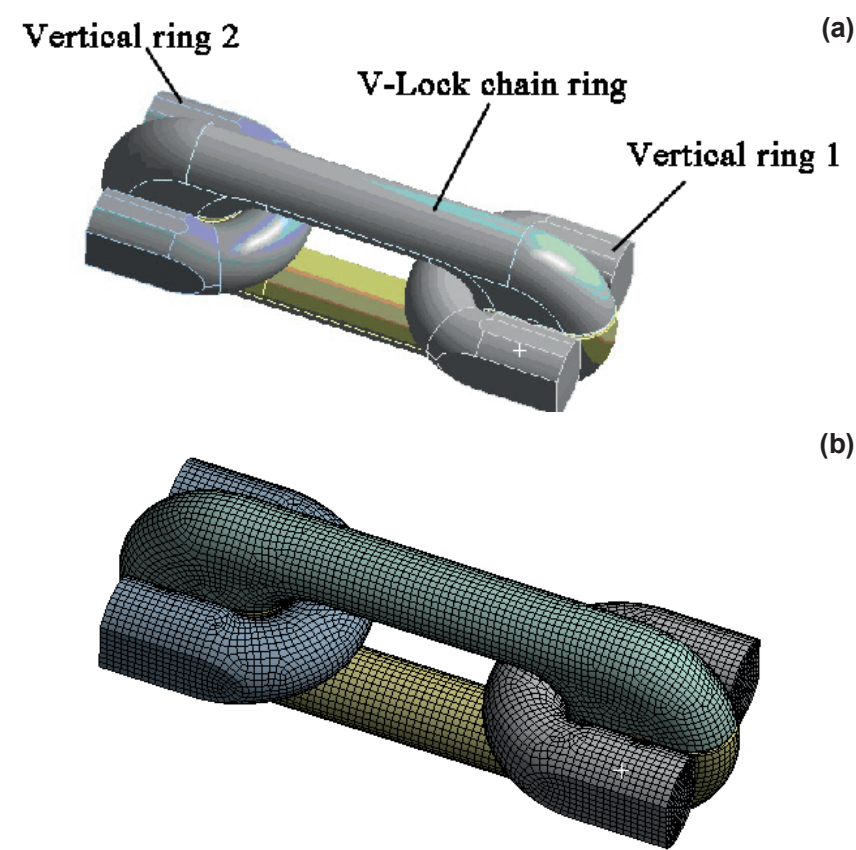

Fig.4 (a) Simplified model of link chain system and (b) Finite element model of link chain system. 


\section{FINITE ELEMENT ANALYSIS OF LINK CHAIN}

The static analysis result exported form ANSYS Workbench is imported into ncode DesignLife which is the advanced fatigue analysis module of ANSYS. The tensile force is used as the random disturbing load. Goodman theory is used to correct the damage calculation for the meaning stress. The fatigue life and damage cloud pictures of the V-lock chain ring for mining obtained in ncode DesignLife are shown in Figure 5 and Figure 6.

Figure 5(a) shows that the minimum fatigue life of the V-lock chain ring is 1441 cycles which are caused by neglecting the fillet, but this isn't the real life of the link chain. For the convenience of the fi-nite element analysis, fillets of the $\mathrm{V}$-lock chain ring for mining are neglected which causes the stress con-centration. Therefore, the minimum fatigue life should be 44180 cycles in fact. Figure 5(b) shows that the real minimum fatigue life is 26110 cycles. 1cycle is equal to 120 s, so the minimum fatigue life of the link chain under the tensile force $\mathrm{F}_{1}$ and $\mathrm{F}_{2}$ are respectively 61.4 days and 36.3 days. The fatigue life under the tensile force $\mathrm{F}_{2}$ is shorter than that under the tensile force $\mathrm{F}_{1}$ through comparing Figure 5(a) and Figure 5(b) which shows that the tensile force $\mathrm{F}_{2}$ causes greater damage, namely the fatigue damage of the link chain on the side of the motion direction of the plow head is larger than that on the other side. The short fatigue life region of the V-lock chain ring for mining is mainly concentrated in the transition region between the medial straight edge and arc which is the same as the welding ring and forging ring. This region will be the crack source, so the fracture failure is easier to produce in this region.
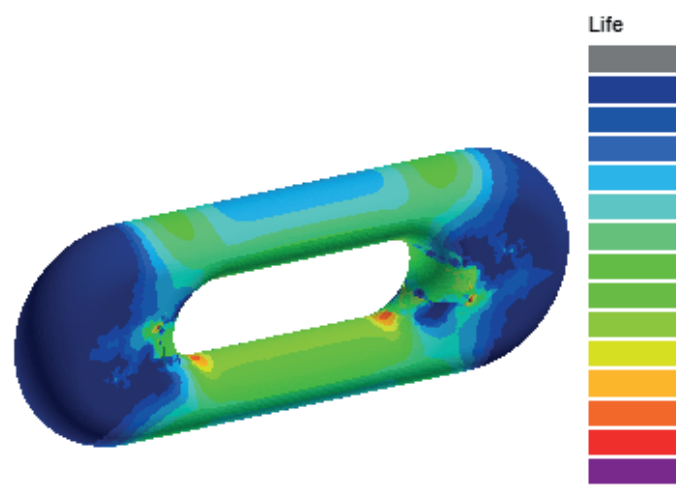

No Data Beyond Cutoff $3.248 \mathrm{e}+019$ $3.248 \mathrm{e}+019$
$1.059 \mathrm{e}+018$ $3.454 \mathrm{e}+016$ $1.126 \mathrm{e}+015$ $3.673 \mathrm{e}+013$ $1.198 \mathrm{e}+012$ $3.906 e+010$ $1.274 \mathrm{e}+009$ $4.154 \mathrm{e}+007$ $1.355 \mathrm{e}+006$ $4.4180+004$ $1.441 \mathrm{e}+003$ Static Failure

Life

(b)

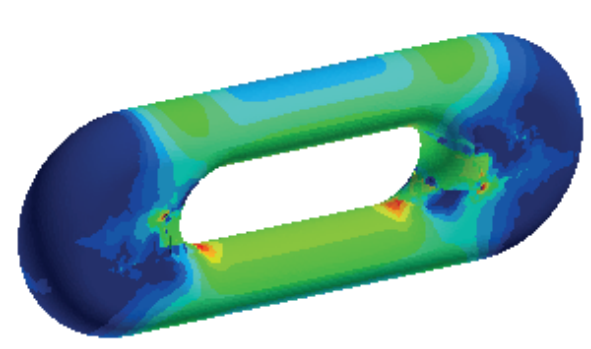

No Data Beyond Cutof $3.093 e+019$ $9.617 \mathrm{e}+017$ $2.990 \mathrm{e}+016$ $9.297 e+014$

$2.890 \mathrm{e}+013$ $8.987 \mathrm{e}+011$ $2.794 e+010$ $8.688 \mathrm{e}+008$ $2.701 \mathrm{e}+007$ $8.398 \mathrm{e}+005$ $2.611 e+004$ $8.119 e+002$ Static Failure

Fig.5 (a)Life of V-lock chain ring for mining under tensile force and (b) life of V-lock chain ring for mining under tensile force
The damage is the ratio of the design life and probable life. The maximum damage region is equivalent to the minimum fatigue life region. Figure 6 shows that the damage values under different tensile forces are less than 1 , namely the design life is less than the probable life which shows that the V-lock chain ring for mining meets the design requirements.

The minimum fatigue life of the V-lock chain ring for mining calculated by the finite element method actually represents cracks have appeared on the link chain at this moment. But this can't express the link chain has lost the work ability. The process from the crack initiation to the complete failure of the V-lock chain ring for mining needs some time.

According to the data provided by manufacturers and coal enterprises, we can know that the average service life of the V-lock chain ring for mining used in the plough is 3.5 months.
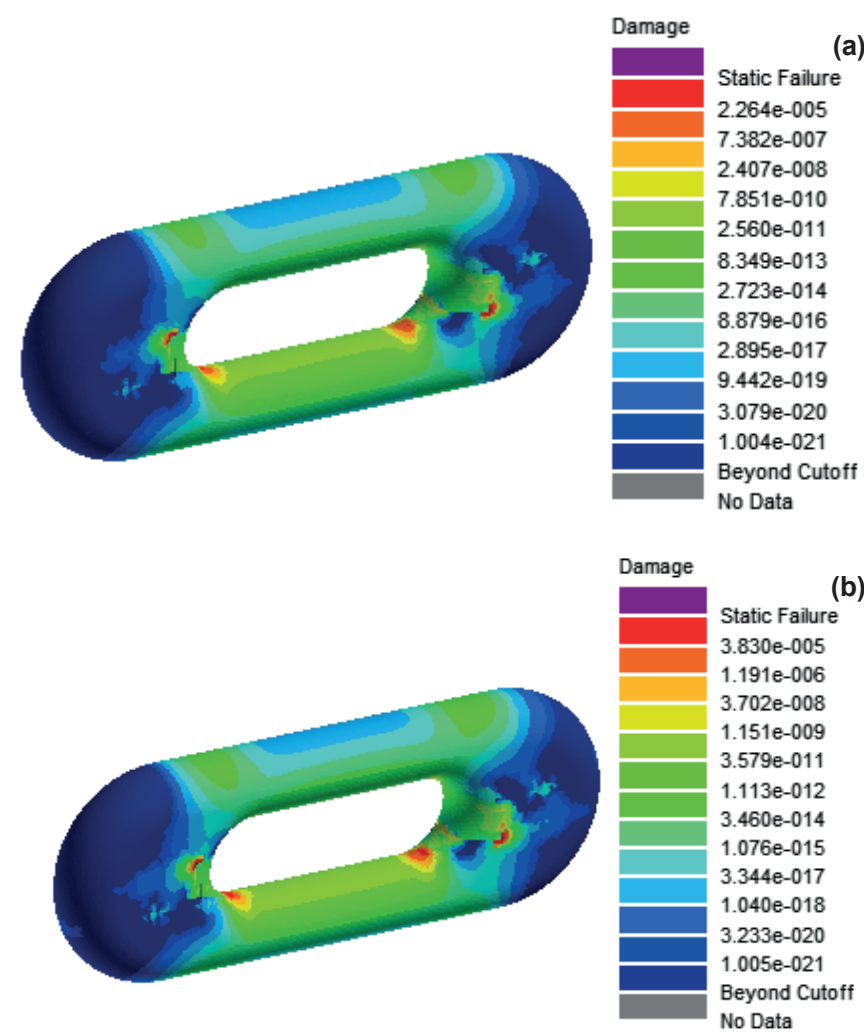

Fig.6(a) Damage of $V$-lock chain ring for mining under tensile force and (b) damage of $V$-lock chain ring for mining under tensile force

\section{SENSITIVITY ANALYSIS OF V-LOCK CHAIN RING FOR MINING}

\section{OVERLOAD SENSITIVITY ANALYSIS OF LINK CHAIN}

To study the overload sensitivity of the V-lock chain ring for mining, the scale factor of the load is used as the varying parameter. The overload working conditions are simulated by a change of the value of the scale factor. The curve of data points of the minimum fatigue life is plotted by using MATLAB. The overload sensitivity curve of the $\mathrm{V}$-lock chain ring for mining is shown in Figure 7(a). Figure 7(a) shows that the minimum life decreases with the increase of the scale factor. The minimum life decreases soon in the scale factor range from 0.6 to 0.9 . In 
the scale factor range from 0.9 to 1.5 , the minimum life changes slowly which shows that the V-lock chain ring for mining is insensitive to the overload, namely the link chain has strong anti-fatigue performance.

\section{RESIDUAL STRESS SENSITIVITY ANALYSIS OF LINK CHAIN}

The V-lock chain ring for mining will produce the residual stress in the manufacturing process. The residual stress sensitivity curve of the link chain is shown in Figure 7(b). Form Figure 7(b), it can be seen that the minimum life decreases with the increase of the residual stress, and the general trend of the curve is linear. The influence of the residual stress isn't very significant.
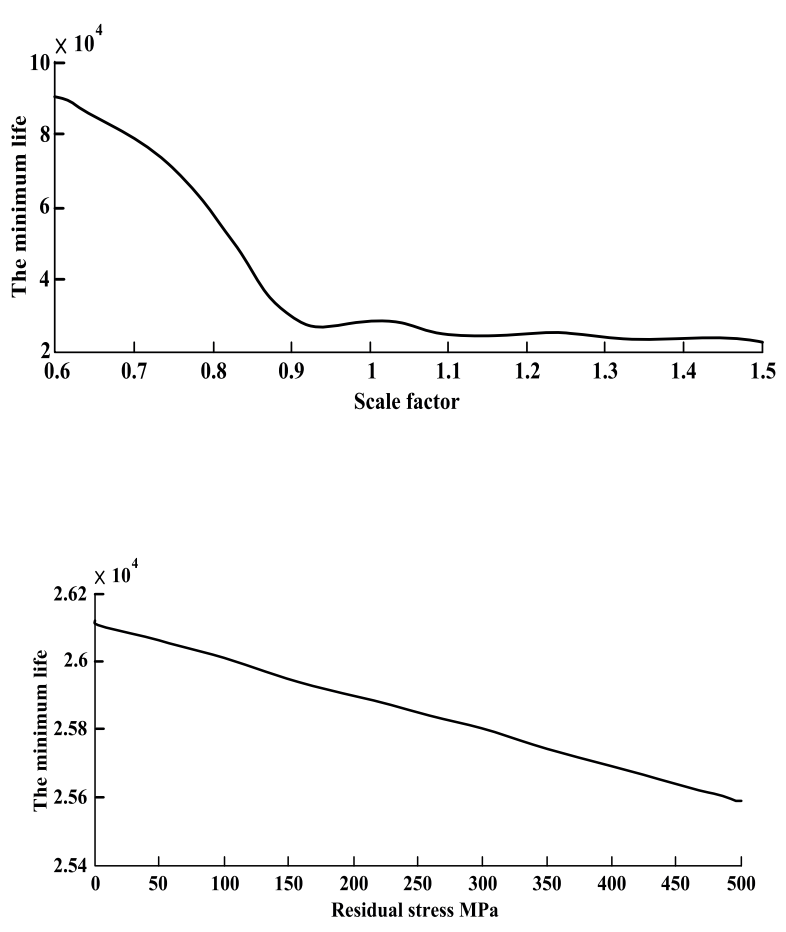

Fig.7(a) Overload sensitivity of link chain and (b) residu-al stress sensitivity of link chain

\section{SURFACE ROUGHNESS SENSITIVITY OF LINK CHAIN}

The surface quality has a significant influence on the fatigue life in the high cycle fatigue, but the influence is little in the low cycle fatigue. This is because the relatively high load is the dominant factor of the whole fatigue process in the low cycle fatigue. The minimum life increases exponentially with the increase of the surface roughness factor, as shown in Figure 8. The V-lock chain ring for mining is sensitive to surface roughness. Therefore, improving the surface processing quality is a main way to prolong the service life of the link chain.

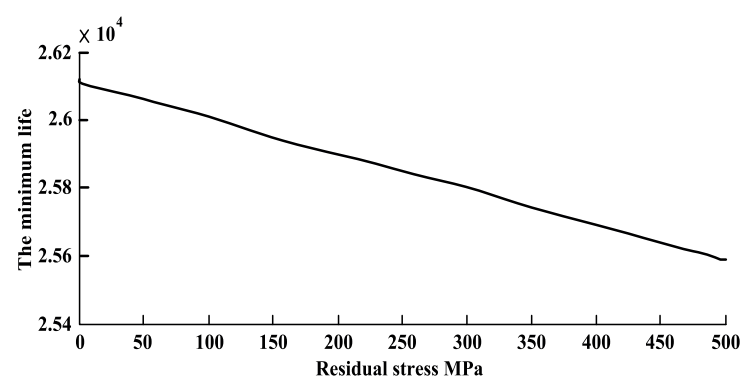

Fig.8 Surface roughness sensitivity of link chain

\section{CONCLUSION}

1) The tensile force of the chain transmission system is a dynamic changing process in the plough. The bilateral tensile force of the plow head is different. The tensile force on the motion direction side can cause the larger damage.

2) The short fatigue life region of the V-lock chain ring for mining is mainly concentrated in the transition region between the medial straight edge and arc.

3) Improving the surface processing quality can significantly prolong the service life of the V-lock chain ring for mining.

4) The V-lock chain ring for mining has strong anti-fatigue performance.

5) The analysis results in this paper can provide the theoretical basis for prolonging service life and the selection of the optimum maintenance period of the V-lock chain ring for mining.

\section{ACKNOWLEDGEMENT}

This work was partially supported by the Nation-al Natural Science Foundation of China (Grant No. 5150041043) and Key Laboratory of structural analysis for industrial equipment(GZ1402) and Foundation of the State Key Laboratory of Mechanical Transmissions (SKLMT-KFKT-201515).

\section{REFERENCES}

1. Zhang, Q.; Fu, Y, F.; Hu, N., (2013). Study of dynamic characteristic of mining V-lock chain ring under impact load caused by stuck chain. Journal of Hefei University of Technology (Natural Science), 36, 401-404.

2. Shiuh-Chuan, (2000). Fracture analysis of inter facial crack by global-local finite element. International Journal of Fracture, 2, 177-193. 
3. Zhang, Q.; Fu, Y, F.; (2012). Critical damage of high strength ring chain under temperature/me-chanical loads. Materials Review, 26, 163-170.

4. Mao, J.;Cao, Y, L.; Jiang, G, Q., (2000). Analyzing the strength and optimizing the structure of the link chain. Machine Design and Research, 21, 65-68.

5. Zhang, Y, B.;Guo, W.;Gao, Y, P., (2011). Applica-tion and development of chain connector. Coal Mine Machinery, 32, 3-5.

6. Zhang, Q.; Fu, Y, F.; (2013). Reliability-based ro-bust design for kinematic accuracy of the plow plane chain mesh with arbitrary distribution param-eters base on NSGA-II algorithm. Journal of China Coal Society, 38, 505-511.

7. Ren, C, Y.;Zhao, C., (2010). Structure Analysis based on flat type connector units of scraper conveyor. Journal of Machine Design, 27, 74-76.

8. Zhang, Q.; Li, S., (2012). Topological optimization of pick structure based on LS-DYNA. Disaster Ad-vances, 5(4), 187-193.

9. Yang, S, C.; Wang, G, Q;Zhang, Y, B., (2012). Fi-nite element analysis and design for connecting ring of scraper conveyor. Coal Mine Machinery, 33, 105-107.

10. Zhang, Q.; Fu, Y, F.; Hu, N., (2014). Dynamic simulation of scraper chain system reliability and selection of optimum maintenance period. Machine Design \& Research, 30(2), 148-153.

11. Kang, X, M.; Li, G, Q., (2009). Single-degree of freedom dynamic model of coal plough and its simulation. Journal of Vibration and Shock, 28, 191-195.

12. Zhang, Q.; Wang H, J.; Fu, Y, F.; Gong, J., (2015).Mechanical property and fatigue life prediction of sprocket in scraper conveyor. Journal of Mechanical Strength, 37(2), 328-336.

13. Li, X, H.; Liu, X.;jiao, L., (2010). Dynamic simulation of sliding coal plow under different working conditions. Journal of China Coal Society, 35, 1202-1206.

14. Kang, X, M.; Li, G, Q., (2010). Prediction of fatigue life of coal plow chain under stochastic dynamic load. Journal of China Coal Society, 35, 503-508.

15. Ramaswamy S.N.; Nampoothiri N.V.N.; Sckar T., (2013). Mitigation of accidental disasters in fire-works industries -construction management approach. Disaster Advances, $6,41-50$.

16. Wei, G., (2013). Numerical analysis of DOT shield $45^{\circ}$ crossing the masonry structure buildings. Disaster Advances, 6, 20-25.
17. Zhang, Q.; Fu, Y, F., Nie, G, Q., (2013). Study of mechanical properties of V-lock chain ring under dynamic load. Journal of machine design, 30, 13-16.

18. Wu W.F.; Ni C.C., (2004). Probabilistic models of fatigue crack propagation and their experimental verification. Probabilistic Engineering Mechanics, 19, 247-257.

19. Zhang, Q.; Xu, M, J., (2014). Study on fatigue life of plow bit under different planning parame-ters. Strength of Materials, 46(2), 262-269.

\section{CONTACT WITH AUTHOR}

Qiang Zhang

Email:lgdjx042@126.com

Tel.: +0086 0418-3350517;

Fax: +0086 0418-3350517

Haijian Wang

Email:qingseyuji2010@163.com

Tong Guo

Email:45381111@qq.com 